\title{
Arbor
}

\section{De las Reales Caballerizas a la Colección de Carruajes del Patrimonio Nacional}

\section{Eduardo Galán Domingo}

Arbor CLXIX, 665 (Mayo 2001), 221-238 pp.

Entre las grandes colecciones históricas que alberga el Palacio Real de Madrid, quizás ninguna sea hoy tan desconocida como la de Carruajes, herencia material recibida de las Reales Caballerizas, que era una de las principales dependencias al servicio de la Corona mientras el Palacio fue la sede habitual de los Monarcas. Esta relativa oscuridad se ha debido, tanto a la magnificencia de otros conjuntos, tapices o armaduras, como a la falta de estudios serios sobre un tipo de objeto cuya naturaleza se sitúa entre su función utilitaria y su valor como obra de arte. Los escasos textos españoles sobre este tema se dividen por igual entre aproximaciones nostálgicas al pasado (Soler, 1952; Ramos, 1977), textos divulgativos muy pocos monográficos (Turmo, 1969), y la mayoría, encuadrados en el marco de estudios más amplios (Navas, s.a.; Calvert, 1907). En consecuencia apenas contamos con un único catálogo para piezas en colecciones públicas españolas (Rodrigo, 1991).

Sin embargo, no siempre fue así. Desde las últimas décadas del siglo pasado, las Caballerizas se abrían al público con un cierto sentido museístico, que fue ganando carta de naturaleza con el tiempo, de modo que podemos decir que, junto con la Real Armería, las Caballerizas constituyeron el primer Museo de los Palacios Reales españoles, fermento de la actividad mantenida por el Patrimonio Nacional. En algún texto coetáneo, tanto de viajeros extranjeros (Doré y Davillier, 1984), como de artículos redactados por personal de la propia Casa Real, se le consideraba uno de los museos más populares de Madrid. 
Siempre se ha estimado a los espacios de servicio, dentro de los Palacios Reales, como zonas de valor muy inferior a los grandes salones donde el Monarca desarrolla su vida y representación cotidianas. Sin embargo, y a pesar del escaso interés que ha despertado su estudio, no cabe duda que, en el caso concreto de las Caballerizas, nos encontramos ante un departamento de importancia crucial para el desarrollo de la función real. En efecto, y de cara a la mayoría de sus súbditos, la manifestación del poder del Rey se limitaba a la decoración externa de sus Palacios y a la proliferación de los blasones reales en las fachadas de los edificios públicos o en la moneda. La vida palatina y cortesana se desarrolla de puertas hacia dentro, allí donde la generalidad del pueblo no tiene nunca la ocasión de acceder siquiera de visita. El Salón del Trono, la Cámara de Gasparini o los Gabinetes de Porcelana, que hoy visitamos, estaban reservados a una fracción muy reducida de la sociedad. Cuando de verdad el pueblo tiene la ocasión de ver al Rey y apreciar directamente su poder, es en las contadas ocasiones en las que abandona su palacio y atraviesa las ciudades y pueblos de su reino con motivo de un viaje, una entrada triunfal o el desarrollo de alguna ceremonia política o religiosa. Pues bien, el departamento encargado de organizar, mantener y prestar el servicio necesario para que esas salidas pudieran realizarse con el esplendor necesario, eran las Caballerizas Reales.

Hasta su desaparición en 1931, y en sus diferentes ubicaciones, las Caballerizas se fueron encargando de un creciente número de funciones dentro de la Casa Real, absorbiendo, aunque sin mezclar entre sí, ni anular su propia personalidad, servicios tan diferentes como la Armería, la Casa de Caballeros Pajes, la Ballestería o las Reales Yeguadas de Aranjuez y Córdoba, además de la red de establecimientos y depósitos de ganado, carruajes y alojamientos para el personal, necesarios en los diferentes Reales Sitios a los que la Corte se desplazaba, periódicamente, desde el siglo XVIII.

\section{Una institución}

Las Caballerizas constituyen, al menos desde la reorganización de la Casa Real de Castilla por Felipe el Hermoso, según el modelo de Borgoña, una de las grandes divisiones funcionales de la misma. El Caballerizo Mayor, a cuyo cargo se encontraban, era uno de los tres grandes cargos palatinos, junto al Mayordomo Mayor y al Sumiller de Corps. Es por ello que, a lo largo de su historia fuera un puesto 
De las Reales Caballerizas a la Colección de Carruajes...

ocupado por miembros de la alta nobleza, aun cuando nunca llegase a ser hereditario, como prácticamente sucedió en la Francia borbónica. En el siglo XVIII, cuando Felipe V adapta la estructura de la Casa Real Española al modelo francés de Luis XIV, se refuerza esta posición palatina, y el servicio de Caballerizas se vuelve más importante, porque los Reyes comienzan a desarrollar un sistema anual de desplazamientos o «jornadas» entre las Residencias Reales que rodean la capital. Este hábito implicaba la necesidad de un enorme volumen de movimientos coordinados de la Corte, que se traslada con los Monarcas, requiriendo gran número de animales, carruajes y personal de servicio, así como equipajes y provisiones para las personas y el ganado, junto con alojamiento y pago de salarios extraordinarios. A ello se añade el problema del mantenimiento de los caminos que los enlazaban y las necesidades de todo tipo que tan gran número de población flotante causaba en cualquier pequeña población de la época.Todo ello, junto con la frecuencia de desplazamientos alcanzado a lo largo del siglo XVIII, culminó en una independencia funcional de las Caballerizas respecto de otros servicios de la Casa Real, consumiendo un elevado presupuesto propio que incluía la realización de obras por separado de la dirección de obras generales de la Casa Real.

Además, del Caballerizo Mayor dependía un complejo entramado de servicios, algunos directamente vinculados al Palacio Real de Madrid, y otros periféricos. A la cabeza de esta administración estaba el Veedor General que era interventor y contable de los gastos de la Caballeriza. Después se configuraban una serie de departamentos denominados cuarteles que incluían, el de caballos de monta, denominado "Regalada", los de caballos y mulas para tiro de coches, el Guadarnés general, y los Picaderos. Paralelamente se agregaban los empleados relacionados con los cortejos y actos ceremoniales cuya organización se vinculaba a las Caballerizas, Reyes de Armas, maceros, timbaleros y clarineros; la Armería Real; la Ballestería; la institución de la Casa de Caballeros Pajes; y, finalmente, las Yeguadas de Aranjuez y de Córdoba que fueron dependencias más o menos directas según las épocas del Caballerizo Mayor.

El conjunto fue generando una plantilla que no dejó de crecer y modificarse durante los dos últimos siglos. En esta evolución resulta interesante ver, cómo en principio, abundan los dependientes y criados mientras que los artesanos, denominados «oficios de manos», son personal externo a la plantilla de las Caballerizas, profesionales gremiales que realizaban contratas con las Caballerizas y trabajaban fuera de éstas. Sin embargo, a lo largo del siglo XIX, estos artesanos se van 
integrando en las plantillas y acabarán por establecer una línea de profesionales que han llegado hasta nuestros días, integrados en el Patrimonio Nacional, y: que constituyen, en mi opinión, uno de sus mayores lujos cuya pérdida debiera evitarse a toda costa.

\section{Un edificio}

Esta organización tuvo un brusco final al proclamarse la Segunda República. No sólo por la disolución de la organización palatina en la que estaba integrada y por la pérdida de su función, sino por la propia desaparición física del inmueble en el que radicaba, y que formaba parte indisoluble del Palacio Real de Madrid, tal como Carlos III y su arquitecto Sabatini proyectaron acabarlo. Sólo las personas de mayor edad podrán recordar el enorme edificio que albergaba las Caballerizas, en cuyo solar se encuentran ahora los Jardines de Sabatini. El edificio fue cedido por el Gobierno de la República al Ayuntamiento de Madrid, en 1932, y demolido dos años después, con el fin de rectificar y mejorar el trazado de las Calles de Bailén y de la Cuesta de San Vicente, a la vez de permitir la mejor contemplación de la fachada norte del Palacio (Fernández, 1993). Polémicas y segundas lecturas aparte, este derribo puso de manifiesto la urgencia de crear un Museo que como tal contuviese la Colección de Carruajes de gala reunidos por la Corona a lo largo de varios siglos. Los primeros proyectos ya fueron planteados durante el periodo republicano, aunque quedasen abandonados con el comienzo de la Guerra Civil.

Hemos comenzado la historia por el final, y el edificio de Sabatini bien merece un comentario más detallado. Como es sabido, cuando Carlos III llega a Madrid, la fábrica del Palacio Real Nuevo está ya muy avanzada, aunque todavía no sea habitable. No es, desde luego, el Palacio que el nuevo Rey habría deseado, y por eso se plantea hacer numerosos cambios. Entre las necesidades, aún sin resolver, se encuentra la de la ubicación de las Caballerizas, hasta ahora dispersàs entre los viejos edifícios supervivientes del entorno del Alcázar de los Austrias y de las instalaciones del Palacio del Buen Retiro. Fernando VI, dado lo reducido de su familia, apenas se había preocupado del tema, pero por el reglamento de 18 de Marzo de 1749, había diseñado unas Caballerizas muy reducidas, suficientes para sus necesidades y las de la Reina.

Carlos III inicia, rápidamente, la búsqueda del emplazamiento y tamaño idóneo para sus Caballerizas. Desde 1760 hay documentación 
en el Archivo General de Palacio sobre la adquisición de terrenos, la edificación y reparación de diversos edificios en El Pardo, Viñuelas, Buen Retiro y los alrededores del propio Palacio para alojar caballos, personal y carruajes. El 11 de Septiembre de 1761, una nueva reglamentación de las Caballerizas aumenta, notablemente, su volumen, como reflejo de las nuevas necesidades de la familia tan numerosa del Rey, para la cual el propio Palacio resultaba pequeño.

La decisión final sobre la ubicación de las Caballerizas se demoraría aún varios años, quizás porque su creación se concebía como parte de un proyecto mayor de urbanización del entorno del Palacio Real, que sólo parcialmente se vería realizado. Sea como fuese, se optó por la funcionalidad frente a la estética, por un edificio de gran capacidad y de gran sobriedad hacia el exterior. Esta solución, opuesta por ejemplo a la adoptada en Versalles, un siglo antes (Massounie 1998; Roche 1998), permitió que, en su siglo y medio de existencia, apenas sufriese una ampliación significativa, con la edificación de un pabellón para los carruajes denominado, el "Cocherón de Palacio", en tiempos de Fernando VII.

Conocemos relativamente bien estos edificios, tanto por los planos del propio Sabatini depositados en el Archivo General de Palacio (Sancho, 1993), como por las descripciones coetáneas a su existencia (Eguren, 1847). Era una gran construcción irregular, articulada en torno a cinco patios internos, cuyas crujías estaban destinadas a los diferentes servicios, destacando el espacio para el ganado, tanto de monta como de tiro, con capacidad para unos quinientos animales. Asimismo había una gran nave ocupada por el Guadarnés general, espacios para distintos talleres y alojamientos en la parte superior. Además integraba dos picaderos para los ejercicios de monta de la Familia Real y los caballeros pajes. Uno de ellos constituyó, hasta su derribo, el último vestigio del Alcázar de los Austrias, que fue aprovechado en el proyecto de Sabatini (Plaza, 1975; Blasco, 1988). El Cocherón antes citado se añadió, entre ambos picaderos, para cubrir la carencia de espacio y albergar los numerosos carruajes de la Casa Real, que habían dispuesto de espacio en el Palacio del Buen Retiro hasta su destrucción, pero para los que las instalaciones previstas, originalmente, por Sabatini resultaban ya pequeñas.

Con el tiempo, a la población equina se fue sumando una colonia humana cada vez más numerosa, que alcanzaría los quinientos moradores según algunas fuentes (Turmo, 1969). Personal en su mayor parte de las propias Caballerizas, pero también de otras dependencias de la Real Casa. Sin duda, el desalojo y diáspora de estas familias, 
como el de los habitantes de las plantas superiores del propio Palacio, constituye uno de los aspectos más desconocidos de los cambios que trajo consigo la instauración de la Segunda República en relación con los bienes de la Corona. Por lo que respecta a las Caballerizas, supuso su total desarticulación y, sumado a los efectos de la posterior Guerra Civil, la pérdida total de personal cualificado para mantener en buen estado el conjunto de vehículos y guarniciones heredados del periodo anterior.

\section{Una colección con historia propia}

A diferencia de lo que suele suceder con las colecciones de nuestros Museos, compuestas por sucesivas aportaciones que las han ido enriqueciendo, las del Patrimonio Nacional pueden leerse mejor al contrario: desde la perspectiva de las sucesivas crisis que, a lo largo de la Historia, han ido mermando, paulatinamente, su volumen. En la mayor parte de los casos esta merma ha servido para desarrollar nuevas instituciones museísticas, desde el Museo del Prado hasta el Museo Arqueológico Nacional o el Museo de América. Sin embargo, en lo referente a los carruajes puede hablarse de pérdida sin paliativos, de tal forma que la Colección actual es el resultado de la supervivencia parcial de un conjunto muy superior.

Vamos a plantear esta visión desde el punto de vista de los momentos críticos en la existencia de las Reales Caballerizas, sin intentar hacer de ello un lamento por las piezas desaparecidas, sino como herramienta para explicar la forma en la que un conjunto, aún hoy excepcional, ha devenido en colección de museo una vez perdida su función original. De esta forma habrá que referir cuatro momentos cruciales en la existencia de las Caballerizas que explican su situación y sus efectivos actuales: el incendio del antiguo Alcázar de los Austrias en 1734; el convulso periodo de la Guerra de la Independencia (1808-1814) y sus consecuencias; la etapa entre el destronamiento de Isabel II y la Restauración de Alfonso XII (1868-1875); y, naturalmente, la caída de la Monarquía en 1931 y la desaparición física de las Caballerizas.

Antes que nada, debemos referirnos a las Caballerizas anteriores al advenimiento de los Borbones en 1700. Las noticias que conservamos son parciales y muy dispersas, en buena medida, porque los desplazamientos largos eran difícilmente realizables en carruajes, dada la naturaleza de los caminos de la época. Se aprovechaba, siempre que era posible, la navegación fluvial o costera antes que el azaroso viaje 
terrestre (Uriol, 1990). Y no sólo los caminos eran malos, sino que a menudo faltaban infraestructuras para garantizar el paso de ríos y otros accidentes geográficos: por ejemplo, Felipe IV en su viaje a Andalucía, al poco de acceder al trono, estuvo a punto de ser llevado por la corriente del Guadiel en su carruaje (Herrera, 1624).

A pesar de todo una carroza de este periodo ha sobrevivido casi intacta hasta nuestros días, como joya del Museu Nacional dos Coches de Lisboa. Se trata del carruaje, de segura fabricación española, en el que Felipe III de España (II de Portugal) visitó, en 1619, su otro reino peninsular. Lujosamente decorado, como corresponde a un vehículo real, este coche es un magnífico ejemplo de los vehículos de madera y cuero que predominaron en España hasta finales del siglo XVII, y uno de los escasísimos ejemplares, anteriores al siglo XVIII, que han llegado hasta nosotros.

Uno de los mayores lujos de la Colección del Patrimonio Nacional, es, precisamente, el de disponer de dos piezas del siglo XVI que pueden considerarse únicas en su género, aunque ninguna de ellas sean, estrictamente, carruajes. La primera es la litera del Emperador Carlos $\mathrm{V}$ que se custodió, durante siglos, en la Real Armería, y que corresponde a un tipo de vehículo que dominó los difíciles caminos de Europa hasta bien entrado el siglo XVII. La segunda es la silla de manos expresamente construida para Felipe II durante sus últimos años, para desplazarle con el mínimo de incomodidad, y que es el precedente directo de las piezas homólogas con profusa decoración del Barroco y Rococó.

Con Felipe V llegaron a España, con mucha más fuerza que hasta entonces, las influencias francesas en todos los ámbitos. El desarrollo en el uso del carruaje, como medio de transporte cortesano, data, indudablemente, de este reinado, y caben pocas dudas de que a él debemos atribuir la incorporación de la Carroza Negra, el carruaje más antiguo que conservamos correspondiente al estilo de los vehículos de gala de la corte de Luis XIV, en la segunda mitad del siglo XVII. Pese a su cronología, esta pieza no se cita nunca en los inventarios correspondientes a la época de Carlos II, y, dado su diseño típicamente francés, hay que pensar que llegase a Madrid como parte de los bienes del primer Borbón. Aún hoy impresiona la talla que cubre completamente la caja, realzada por el color negro brillante que sugirió su atribución, en los antiguos inventarios, como el "Coche de Juana La Loca», con el que ya fue conocida en publicaciones desde el siglo XIX, como en La España Artística y Monumental, de Pérez Villaamil y Escosura. 
En la Navidad de 1734 se produce el famoso incendio que acabaría con el Alcázar dando lugar a la construcción del Palacio Real actual. El hecho de que sólo se haya conservado la Carroza Negra, entre los vehículos anteriores a esta fecha, ha dado alas a la extendida idea de que la mayor parte de las Caballerizas sucumbiría en dicho incendio (Turmo, 1969: 34). Sin embargo, nada más lejos de la realidad, pues los edificios y servicios periféricos del Alcázar apenas se vieron afectados por el fuego. Hay que tener en cuenta el hecho, ya mencionado, de que muchos de los carruajes de la Casa Real se albergaron, durante todo el siglo XVIII, en el Buen Retiro y en otras localizaciones alquiladas, según las necesidades de cada momento, a falta de un establecimiento centralizado, cuyo papel no podían cumplir las Caballerizas de Felipe II, por sus pequeñas dimensiones, a pesar de los añadidos. Carruajes de este momento siguen siendo citados por los registros de la época de Carlos III, lo cual, indirectamente, nos informa sobre su supervivencia. Así pues, nos encontramos ante un pequeño espejismo historiográfico que conviene olvidar en el futuro.

El resto del siglo XVIII conocerá una extraordinaria evolución en el uso del carruaje, dentro y fuera de la Corte, tanto en su uso ceremonial como en el diario, desplazando, finalmente, a las literas que habían conocido su mayor desarrollo en la centuria anterior (Madrazo, 1984; Soler, 1952). A la vez tendrán su apogeo otros vehículos para desplazamientos cortos, como las sillas de manos que, del uso para transporte de enfermos, pasarán a cubrir las necesidades de movimientos urbanos, y se convertirán en objetos de lujo insustituibles en las Cortes europeas a partir del Rococó.

Es la época de las grandes carrozas cubiertas con profusas molduras talladas y doradas, ornadas con tableros pintados a menudo con temas mitológicos o alegóricos, y vestidas, interiormente, con ricos terciopelos, que aparecen en las numerosas pinturas y descripciones de la época. Los inventarios del reinado de Carlos III reflejan la existencia simultánea de hasta dos centenares de carruajes y sillas de manos en las Caballerizas de Palacio. Sin embargo, prácticamente, nada queda de esta gran época en la actual Colección del Patrimonio Nacional, con la excepción de dos sillas de manos de extraordinaria calidad, siendo casi segura la atribución de los paneles de una de ellas, a la mano de Corrado Giaquinto (Jiménez, 1977)

Esta carencia, que justificaremos a continuación, ya era sentida a comienzos del siglo XX, cuando las exposiciones internacionales comenzaban a exhibir muestras de un arte que el automóvil amenazaba con desplazar al olvido (Belloni, 1901), y, sobre todo, a partir de la 
creación del Museu dos Coches Reais de Lisboa en 1905 (Bessone, 1993). Quizás por ello el Marqués de Viana, Caballerizo Mayor de Alfonso XIII, se ocupó de conseguir para la Colección Real española un vehículo de esta época con el que cubrir este notable vacío. Fue ésta una berlina procedente de la Casa de los Marqueses de Alcántara, en Écija, adquirida en 1913, que ha pasado a ser conocida como la Berlina Dorada: es un carruaje típico del segundo tercio del siglo XVIII.

Hay que señalar lo difícil del empeño, incluso, en aquella época, pues hoy sólo podemos citar, en España, otros dos vehículos de cronología y calidad semejantes, uno en Navarra perteneciente a los Marqueses de San Adrián, y otro en Valencia que fue de la casa de los Marqueses de Dos Aguas (Rodrigo, 1991). Nuevamente tendremos que mirar hacia Lisboa para encontrar carruajes salidos de las Caballerizas Reales Españolas y conservados en la actualidad, como algunos de los que llevaron las Infantas casadas con príncipes portugueses a lo largo de la centuria: María Ana Victoria, en 1729 (Lozano, 1991) y Carlota Joaquina, en 1785 (Herrera, 1786; Botto, 1909).

La segunda mitad del siglo XVIII es, sin duda, el gran momento del carruaje, tanto en su evolución técnica como en su calidad artística. Se suceden las innovaciones, en cuanto a la suspensión, con la incorporación de los resortes de muelles, las ruedas que añaden las llantas de una pieza fijadas en caliente, y la disminución de volumen en los juegos, que permite una mayor elegancia formal, a la vez que facilitan el giro de las ruedas delanteras. En consecuencia se multiplica el número de carruajes y la ostentación de los privilegiados a través de su riqueza decorativa y en los tiros de caballos. En este ambiente se suceden las pragmáticas reales destinadas a prohibir estos excesos y a separar a la Casa Real del resto de la sociedad. La Pragmática-Sanción de 9 de Noviembre de 1785, reservaba a los miembros de la Familia Real los tiros de más de dos caballos o mulas, así como la importación de animales de tiro, imponiendo severas penas a quien no lo observase. Hay que decir, sin embargo, que estas normas no se seguían en la práctica y que la propia reiteración de regulaciones casi idénticas es una clara muestra de su ineficacia.

Otra muestra del desarrollo alcanzado por los carruajes, en este periodo, la proporciona el crecimiento en la Corte de los gremios más vinculados a la fabricación de vehículos y atalajes para caballos, es decir, los de maestros de coches y de guarnicioneros (Capella, 1963). Los primeros mantuvieron una larga polémica con el Gobierno sobre la instalación, en la Corte, de maestros extranjeros, autorizada por 
Real Cédula de 30 de Abril de 1772 (López, 1986), en la que se añadía, al corporativismo innato a la organización gremial tradicional, un sentimiento generalizado de infravaloración respecto a las importaciones procedentes del extranjero, y en particular, de Londres y París. Este es el panorama que se deduce de dos pequeños textos de este momento (Anónimo, 1786a y 1786 b) que describen y glorifican a los artífices de un lujoso coche realizado para $\mathrm{M}^{\mathrm{a}}$ Luisa de Parma, entonces aún Princesa de Asturias, cuyo acabado y estilo en nada desmerecerían de los procedentes de los mejores talleres europeos.

Será, precisamente, bajo el reinado de Carlos IV cuando los carruajes alcancen el extremo del lujo y refinamiento posibles. Aunque los encargos a los talleres madrileños son abundantes, la Corte sigue mirando a París para la realización de las berlinas de gala con las que el Rey se muestra en público en ocasiones ceremoniales. Este es un periodo de gran creatividad en la Francia revolucionaria, de la que los monarcas españoles atraen a personajes de la talla de Jean-Démosthène Dugourc, que se habría encargado de dirigir la decoración de algún coche, en París, según cita en su propia autobiografía antes de viajar a España, en 1800 (Junquera, 1979: 28). Sin duda a este periodo corresponde el conjunto de vehículos más espectacular que conservan las Colecciones del Patrimonio Nacional: cinco berlinas de gala datables entre 1790 y 1810, que muestran un compendio de elementos decorativos típicos de los estilos Directorio, Consulado e Imperio, entre los que destacan las cajas cubiertas de placas de verre eglomisé, tan de moda en el mobiliario de los años finales del siglo XVIII.

A la vez que se encargan en París estos vehículos, la Reina confía a artesanos afincados en Madrid la construcción de tres sillas de manos, destinadas a su uso personal en los distintos Sitios Reales. Son piezas magníficas. Destaca la que está completamente cubierta de taracea de maderas finas, cuya calidad en nada desmerece al más delicado de los muebles del periodo, y como tal debió apreciarla la propia Reina, puesto que pagó por ella, en 1795, la exorbitante cantidad de 190.000 reales.

Son años de un cambio de gustos que se refleja en la decoración de los propios Palacios de la Monarquía. Tal vez por ello, se hacen muchos encargos nuevos, a la vez que se arrinconan los grandes coches de gala tallados y dorados del reinado anterior, algunos de los cuales son dados de baja en las Caballerizas a partir de los primeros años del siglo XIX. A esta variación en el gusto se unirá otra circunstancia que acabará por hacer desaparecer el importante volumen de carruajes dieciochescos de las Caballerizas: es el estallido de la Guerra de la 
Independencia, con la abdicación de la dinastía reinante y la entronización de José Bonaparte.

En 1808, al inicio del conflicto, las Caballerizas Reales aún conservan la mayor parte de los coches de gala citados en los inventarios de Carlos III. Sin embargo, cuando Fernando VII ocupa, nuevamente, el trono a partir de 1814, la práctica totalidad de los mismos ha desaparecido. No es ajena a esta situación la partida de, al menos, veintiseis coches en las diferentes comitivas de Personas Reales que marcharon a Bayona en 1808 (Turmo, 1969: 18), de los cuales prácticamente ninguno habría de regresar. Uno de ellos se conserva en el Musée National de la Voiture et du Tourime de Compiègne, en Francia (Moulin, 1992: 182). Algunos desparecerían en los diferentes traslados forzosos a los que se vió obligada la Corte de José I, según los avatares de la guerra, hasta su retirada final. Otros puede que se perdiesen en el incendio del Buen Retiro, aunque carecemos de documentación fiable sobre este extremo. En resumen, aquí está la explicación real de la carencia de piezas de esa época en. la Colección actual.

Fernando VII tuvo que dedicar, desde el primer momento, parte de sus maltrechos recursos a recomponer sus esquilmadas Caballerizas. En un primer momento las circunstancias le obligaron a hacer economías, hasta el punto de adquirir vehículos, incluso de gala, de segunda mano. De esta forma llegó a las Colecciones Reales el denominado Coche de Tableros Dorados, adquirido a los herederos del Marqués de Branciforte en 1816, y que no fue, como pretenderían luego los inventarios posteriores, un regalo del Marqués a Carlos IV durante su mandato como Virrey en Méjico.

Con el tiempo la situación mejoró notablemente, y en las postrimerías de su reinado, Fernando VII hizo numerosos encargos de coches a la moda, tanto para su uso cotidiano como para el ceremonial. Son estos últimos los que se han conservado, constituyendo un verdadero "tren» o comitiva regia, compuesta por tres carruajes. En primer lugar, un landó de gala servía como coche de apertura de desfile, y era ocupado por los gentiles-hombres del Rey o por los Reyes de Armas según las circunstancias del ceremonial. Después, otro coche de gran gala denominado, «de Caoba», estaba destinado al respeto, esto es, ir vacío delante del coche del Monarca, con su mismo tiro y servicio, por si a éste le sucedía algún percance. Y, finalmente, un coche de gran gala denominado, «de la Corona Real», era el vehículo oficial del Rey, y mantendría esta función hasta 1931 (Pineda, 1902).

Es importante señalar un notable cambio de actitud, a la hora de realizar estos coches, respecto a los artífices nacionales. Ahora los coches 
de ceremonia van a ser encargados a maestros asentados en Madrid, y los carruajes, realizados entre 1829 y 1833, van a tener una personalidad común que va más allá de sus semejanzas decorativas. Probablemente esto sea debido a las estrechas relaciones entre los pocos talleres de la Corte que podían asumir encargos de este nivel. Los maestros carroceros, Fernando Rodríguez, Julián González y F. Durán, cuyos nombres aparecen asociados a la realización de estos coches, debieron trabajar muy cerca, unos de otros, para producir un resultado de tal homogeneidad.

A pesar de los avatares políticos, el segundo tercio del siglo XIX será un período de crecimiento y de expansión en las Reales Caballerizas. Se adquieren numerosos carruajes, a la vez que se diversifican sus tipos, especialmente los descubiertos, destinados al paseo como una actividad social de la mayor importancia en todas las capitales europeas del momento. París sigue siendo el centro de referencia y allí son frecuentes los encargos, en especial, los de berlinas y carretelas de gala, aunque también se recurre a los talleres madrileños, algunos de los cuales han evolucionado hasta convertirse en auténticos centros industriales, como el Gran Taller de Recoletos (Capella, 1963: 654-55). También a esta época corresponden los grandes coches de viaje o sillas de postas, destinadas a los desplazamientos largos antes del desarrollo del ferrocarril, que se produciría, paulatinamente, a lo largo del reinado de Isabel II.

La Revolución de 1868 y la caída de Isabel II, así como los acontecimientos que se sucedieron vertiginosamente en apenas seis años hasta la Restauración de Alfonso XII, apenas debieron causar alteraciones significativas en las Caballerizas ni en el conjunto de carruajes existente. Sin embargo, sus consecuencias se sintieron recién comenzado el nuevo reinado. Muchos de los carruajes existentes fueron descartados y se inició una nueva política de adquisiciones, tanto de vehículos nuevos, encargados, en su mayoría, a los principales carroceros parisinos, como Binder o Ehrler, por lo que comenzaron a recibir la denominación genérica de coches de París. Algunos fueron adquiridos, también, de segunda mano para servicios menos importantes.

Los nuevos coches seguían una línea muy similar, que podríamos definir como elegante y discreta. Los juegos se uniformizaron en color encarnado y las cajas en azul oscuro y negro. El único elemento de resalte eran las armas reales pintadas en las puertas. El brillante colorido de la etapa anterior, con sus tonos guinda, limón, café y lacre, desapareció por completo. Este cambio de color puede parecer algo trivial, pero es la manifestación de un cambio de estilo que se mantendría 
en adelante, y que trajo consigo la eliminación de aquellos vehículos que, por su estructura o tipología, no tenían cabida en el nuevo diseño de las Caballerizas, y con ello una nueva ruptura, esta vez natural, en el proceso de gestación de la actual Colección de Carruajes.

Este proceso de unificación formal se desarrolló, principalmente, entre los años 1875 y 1877, y, aún hoy, es perceptible en la Colección Real Española. Su resultado puede apreciarse claramente en la serie de cromolitografías que Sabater dedicó al cortejo nupcial de Alfonso XII y $\mathrm{M}^{\mathrm{a}}$ Cristina de Habsburgo, que tuvo lugar en 1879, y que han sido editadas varias veces desde entonces.

Los últimos años del siglo XIX y los primeros del siglo XX, sólo aportaron algunos coches de uso diario al conjunto heredado de reinados anteriores. El número total de vehículos era bastante elevado, en torno a los ciento treinta, pero su uso fue decreciendo a la par que se imponía el de los vehículos a motor. Alfonso XIII sentía pasión por los automóviles, demasiada incluso, de acuerdo con la opinión de la Corte. Posiblemente por ello, a partir de 1916, no figuran nuevas incorporaciones de coches de caballos a las Caballerizas. Mientras tanto, el número de automóviles crece sin cesar, hasta el punto de ser necesario dividir el Cocherón para habilitar una parte del mismo como garaje.

Con ello llegamos al momento final de las Caballerizas Reales. Ya desde el mismo año 1931, la República se planteó el destino tanto del edificio como de su contenido. Adoptada la decisión de su desaparición, se procedió a dividir los bienes en dos categorías: por un lado quedarían los carruajes, sillas de montar, guarniciones, etc. que se considerasen de valor histórico o artístico, con el fin de constituir un nuevo Museo, posiblemente junto a las colecciones de tapices; por otro, los bienes de uso común que podrían ser vendidos en pública subasta o destinados a otros servicios.

Con este criterio se propuso la venta pública de setenta y tres carruajes, fundamentalmente, los vehículos de diario tales como landós y berlinas, así como los de servicio: jardineras, char-à-bancs y omnibus. No todo el conjunto llegaría a ser vendido, posiblemente, por la escasa utilidad que los coches de gala, o algunos especiales como los infantiles, tendrían para los ciudadanos interesados. Otros objetos como la pequeña Biblioteca o los ornamentos sagrados de la Capilla de San Antonio Abad, revertirían en los servicios paralelos existentes en el Palacio Real de Madrid.

Durante los escasos años de vida de la Segunda República se esbozaron varias ideas destinadas a la definitiva conversión de los carruajes en colección museística (Sancho, 1993; Fernández, 1993). De 
todos ellos no llegaron más que a trazarse los planes, puesto que la Guerra Civil los volvió inútiles. Habría que esperar una década, tras la guerra, para que se plantease la puesta en servicio, nuevamente, de un reducido servicio de Caballerizas, destinado, exclusivamente, a cubrir la ceremonia de acreditación de embajadores. Serían necesarios, casi treinta años, para que, en 1967, se inaugurase el Museo de Carruajes situado en la parte baja del Campo del Moro.

Conforme a su nueva realidad museística, la Colección se benefició de diversas adquisiciones que incrementaron su valor y diversidad. Destaca, en primer lugar, el conjunto de vehículos oficiales de las Cortes Españolas, una serie de berlinas de gala, incluida la del Presidente del Congreso de los Diputados, y un landó que es el único carruaje de fabricación inglesa que poseemos. También se adquirieron una silla de manos del siglo XVIII y un trineo de comienzos del XIX. Además se trajeron, como depósitos, una calesa popular perteneciente al Museo Municipal de Madrid, y, posteriormente, la berlina en la que fue asesinado el General Prim, acompañada del automóvil en el que sufrió un ataque mortal el Presidente del Gobierno, Eduardo Dato. Antes de estas compras la Colección adquirió, tras la Guerra Civil, dos berlinas cupés de gala pertenecientes a sendas casas nobiliarias, procedentes del Servicio de Defensa del Patrimonio Artístico Nacional. A ellas se ha sumado en los últimos años otro carruaje similar, donación del Marqués de Mondéjar.

Actualmente, el Museo de Carruajes está cerrado, en tanto se realizan los trabajos para su nueva instalación en el Museo de las Colecciones Reales, cuyas obras se encuentran a punto de iniciarse. Allí se podrá disponer de espacio para una presentación acorde con la calidad de una Colección Real que puede, sin ningún problema, equipararse a las de cualquier casa real europea (Carnelli y Coppola, 1992; Kugler, 1977; Lierneux y Rommelaere, 1989; Saule, 1997). Hasta aquí su pasado como servicio y su presente como entidad museística. Su futuro está aún por escribir.

\section{BIBLIOGRAFÍA}

Anónimo. (1786a): Descripción de un primoroso Coche que han construido varios Artífices Españoles en competencia con los que vienen de fuera del Reyno. Memorial Literario, Instructivo y Curioso de la Corte de Madrid VIII, 122-130.

Anónimo. (1786b): Las artes triunfantes en el coche de la Serenísima Princesa de Asturias. Madrid, Viuda de Ibarra, Hijos y Compañía. 


\section{De las Reales Caballerizas a la Colección de Carruajes...}

Lozano Bartolozzi, M. M. (1991): Fiestas y Arte Efimero en Badajoz en el siglo XVIII. Cáceres, Universidad de Extremadura.

Bellon, L. (1901): La carrozza nella storia della locomozione. Milán.

Bessone, S. (1993): Musée National dos Coches. París, Reunion des Musées Nationaux y Fondation Paribas.

Bотто, J. M. P. (1909): Promptuario analitico dos carros nobres da Casa Real Portuguesa e das carruagems de gala. Lisboa.

Blasco Castiñeyra, S. (1988): "Tradición y reforma en los alrededores del Palacio Real Nuevo». Carlos III. Alcalde de Madrid. Madrid, Ayuntamiento, 497-526.

Calvert, A. F. (1907): Spanish Arms and Armour. Londres.

Capella Martinez, M. (1963): La industria en Madrid. Ensayo histórico crítico de la fabricación y artesanía madrileñas. Vol. II: Siglos XVIII al XX. Madrid, Cámara Oficial de Industria de la provincia de Madrid.

CARnelli, E. y Coppola, E. a cura di. (1992): «Carroze e Livree». Il patrimonio artistico del Quirinale. Milán.

Doré, G. y DaVIlLIER, Ch. (1984): Viaje por España. Madrid.

EGuRen, J. M. De. (1847): Madrid. En MAdoz, P. Diccionario Geográfico-estadistico-histórico de España y sus posesiones de Ultramar. Tomo X.

Fernández Polanco, A. (1993): «Los alrededores de Palacio en tiempos republicanos». Reales Sitios 115, 17-24.

HeRRerA, B. (1786): Memorias Históricas de los desposorios, viajes, entregas y respectivas funciones de las Reales Bodas de las Serenísimas Infantas de España y de Portugal, la Señora Doña Carlota Joaquina y la Señora doña María Victoria, en el año de 1785. Madrid.

Herreray Sotomayor, J. (1624): Jornada que su Majestad hizo a la Andalucía. Madrid

Jiménez Priego, T. (1977): «Museo de Carruajes de Madrid. Sillas de manos». Reales Sitios 51, 49-56.

Junquera Mato, J. J. (1979): La decoración y el mobiliario de los palacios de Carlos IV. Madrid.

Kugler, G. (1977): Die Wagenburg. Graz.

Lierneux, P. y Rommelaere, C. (1989): Les carroses de la Cour Royale de Belgique et leurs escortes. Bruxelas, Credit Communal.

López CASTÁn, A. (1986): «La construcción de carruajes y el gremio de maestros de coches de la Corte durante el siglo XVIII». Boletín del Museo e Instituto Camón Aznar 23, 99-118.

MadRAZo, S. (1984): El sistema de transportes en España 1750-1850. Madrid.

Massounie, D. (1998): L'Architecture des Écuries Royales du Château de Versailles. París.

Mousin, J.-M. (1992): «Musée national de la Voiture et du Tourisme». En Guide du Musée National du Château de Compiègne. París, Reunion des Musées Nationaux, 171-222.

Navas, Conde de las. (s.a.): Real Palacio de Madrid. Barcelona, Ed. Thomas.

Pineda, A. (1902): Apertura de Cortes. Guía Palaciana. Madrid.

PlaZA, F. J. de la. (1975): Investigaciones sobre el Palacio Real Nuevo de Madrid. Valladolid, Universidad de Valladolid.

Ramos, L. de (1977): Coches, enganches y carrozas. Madrid, tomo III.

Roche, D. (Dir.) (1998): Les Écuries royales du XVIe au XVIIIe siècle. París, Association pour l'académie d'art équestre de Versailles. 


\section{Eduardo Galán Domingo}

Rodrigo Zarzosa,B. (1991): Carruajes del Museo Nacional de Cerámica y Artes Suntuarias González Martí. Catálogo. Madrid.

RodRIGUez y ZuRDo, J. (1861): Manual del sillero y guarnicionero. Madrid, Imprenta de A. Vicente.

Sancho GASPAR, J. L. (1993): «Caballerizas reales o «regalada» junto al Palacio Real». En Francisco Sabatini 1721-1797. Madrid, 221-227.

SAuLE, B. (1997): A guided tour of the Coach Museum. Versailles, Art Lys.

Soler, L. (1952): Historia del Coche. Madrid.

Turmo, I. (1969): Museo de Carruajes. Madrid.

Uriol Salcedo, J. I. (1990): Historia de los Caminos de España. I: Hasta el siglo XIX. Madrid. 
De las Reales Caballerizas a la Colección de Carruajes...

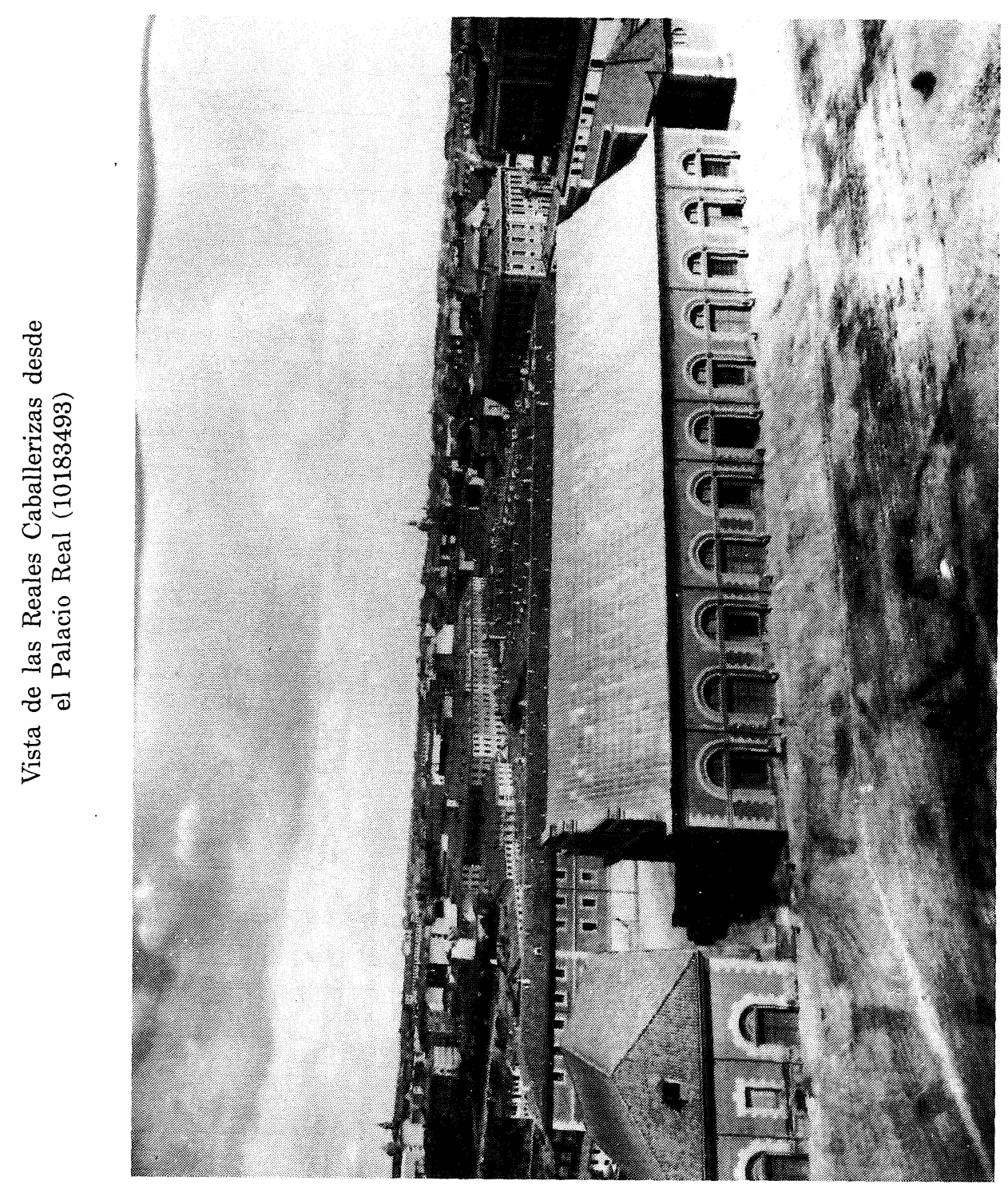




\section{Eduardo Galán Domingo}

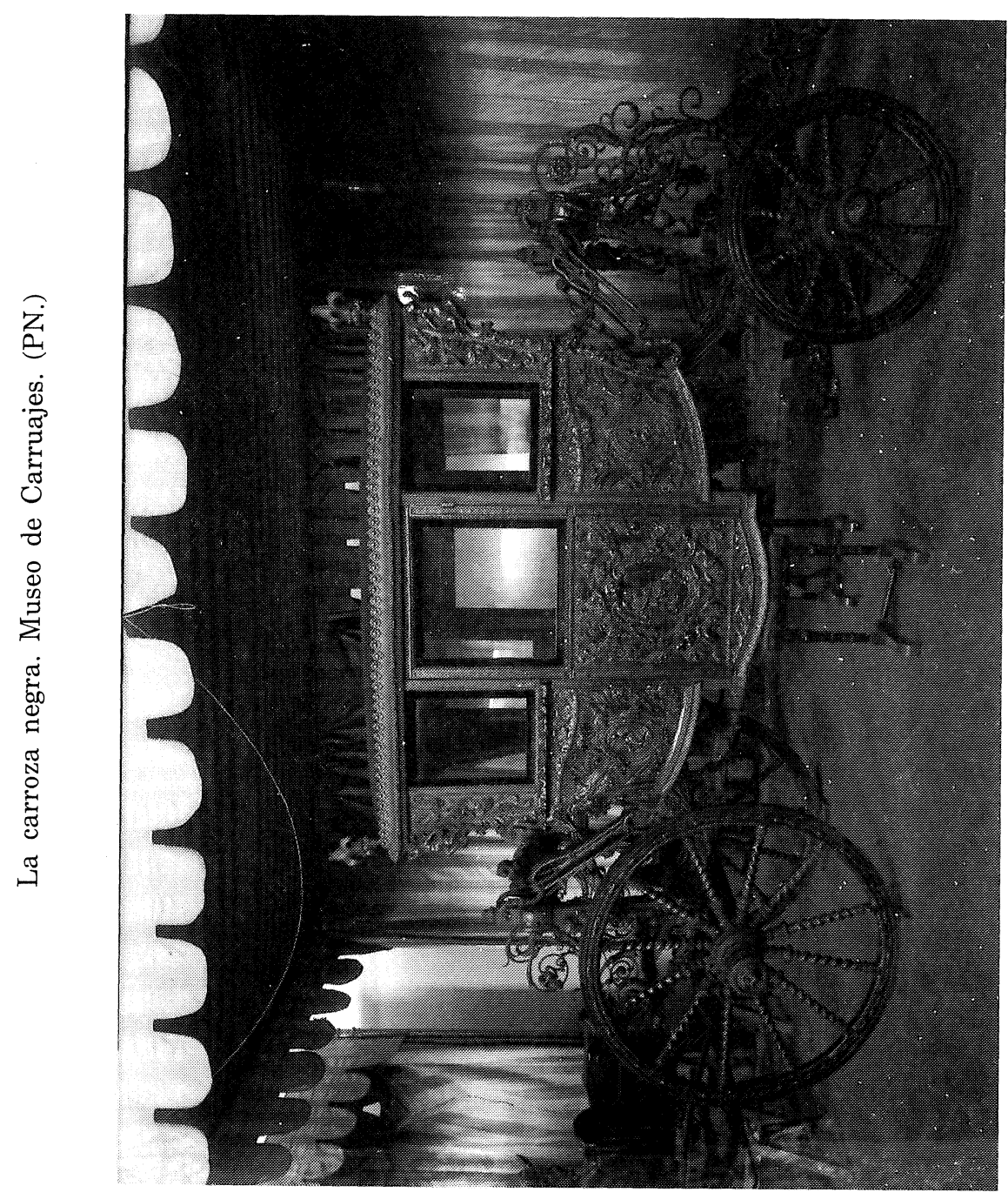

